Patients and methods Have a 94 girls 3-6 years with VV, of which 1 group $(n=52)-V V$ on the background of the UTI, group $2(n=42)$ - isolated VV the assessment of biocenosis of the vagina by microscopy and PCR. Local antibiotic therapy was combined with the use of interferon alpha 2b 500000 ME 2 times a day for 5 days, then 1 time a day -5 days. Prevention of exacerbation of UTI was carried out by phytopreparation CAN-UTI-7 15 drops 3 times a day for 4-6 weeks.

Results In girls with VV and UTI, compared with group 2, the frequency of chronic VV was high $(57.7 \%$ and $29.6 \%$, $\mathrm{p}<0.05)$, the frequency of relapses $(46 \%$ and $14.8 \%$, $\mathrm{p}<0.05)$. In both groups, growth of opportunistic microflora and facultative aerobes $>10^{5} \mathrm{CFU} / \mathrm{ml}$ was revealed. St. epidermidis, E. faecalis were sown more often in isolated VV. The detection rate of E. coli, Candida alb. in group 1 was higher than in group 2. After treatment in group 1, E. coli decreased from $6.8 \pm 0.05 * 10^{6}$ to $1.7 \pm 0.03 * 10^{2} \quad \mathrm{CFU} / \mathrm{ml} \quad(\mathrm{p}<0.05)$, microbial contamination - from $\lg 5.6 \pm 0.07$ to $\lg 2.4 \pm 0.01$ $\mathrm{CFU} / \mathrm{ml}$ (after 1 month), lg $2.1 \pm 0.1 \quad \mathrm{CFU} / \mathrm{ml}$ (after 12 months) $(p<0.05)$.

Conclusion Complex therapy of girls with UTI improves the condition of the vaginal biotope, reduces the rates of microbial colonization and the number of relapses of VV.

\section{P587 IS THE SECOND DOSE ANTIVENOM IN SCORPION STINGS: IS IT EFFECTIVE?}

Çiğdem El*, Mehmet Emin Çelikkaya. Mustafa Kemal University, Hatay, Turkey

\subsection{6/archdischild-2019-epa.921}

Objectives The toxic effects of scorpion stings may be mortal have been known for many years. The progression of poisonings due to scorpion stings is more severe in childhood. These poisonings can cause complications from local skin findings such as pain, redness, and pruritus to fatal complications such as heart failure and pulmonary edema. We aimed to investigate the effectiveness of the second dose antivenom in this study.

Methods 100 patients between 0-17 years who were followed up due to scorpion stings or poisonings in Mustafa Kemal University, Faculty of Medicine, Department of Pediatrics between October 2016 and March 2018 were analyzed for age, sex, season, place of scorpion bite, clinical findings, treatment and follow-up steps, effects of second dose antivenom on clinical progression retrospectively.

Results Of the total 100 patients, 45 were female (45\%) and 55 were male $(55 \%)$. The average age of the patients was 3.5 years (3,6 years for girls and 3,5 years for boys).The most frequent applications were summer (71\%). Bite locations in order of frequency; foots, hands, legs, arms, head-neck, genital area.

Conclusions We have observed that early antivenom therapy reduces the risk of developing systemic symptoms, and even recurrent dose antivenom corrects systemic findings. We think that antivenom should be applied especially in pediatric patients and all patients should be observed for at least 24 hours.

\section{P588} HERPES ZOSTER IN A 2-MONTH-OLD INFANT: A CASE REPORT

${ }^{1}$ Afef Ben Thabet, ${ }^{1}$ Chiraz Regaieg*, 'Amel Ben Hamed, 'Manel Charfi, ${ }^{1}$ Nedia Hmida, ${ }^{2}$ Hamida Turki, ${ }^{1}$ Amira Bouraoui, ${ }^{1}$ Abdellatif Gargouri. ${ }^{1}$ Department of Neonatology, Hedi Chaker Hospital, Sfax, Tunisia; ${ }^{2}$ Department of Dermatology, Hédi Chaker hospital, Sfax, Tunisia

\subsection{6/archdischild-2019-epa.922}

Background Herpes zoster (HZ) is a cutaneous viral infection of the skin that presents in a dermatomal distribution. It represents reactivation of herpes varicella zoster virus that has continued to exist in a latent form in the neurons of the posterior root ganglia. Although it is rare to see $\mathrm{HZ}$ in children, cases have been reported after exposure to varicella zoster in utero or during the first months of life.

Objective The purpose of this report is to present a case of herpes zoster in a 2-month-old infant, conservatively managed without oral antivirals, and its 5 years follow-up, demonstrating no sequelae or recurrences.

Case report A 2-month-old female infant presented with skin lesions in the chest. His mother developed a varicella infection 20 days before delivery. The child was asymptomatic at birth. Physical exam noted a fever and skin lesions made of grouped vesicles on erythematous plaques. The characteristic herpetiform lesions distributed in the dermatome of the left hemi chest. The infant was treated by only local antiseptic treatment. The lesions were completely resolved in 2 weeks. After 5 years of follow-up the child has no sequelae, such as postherpetic neuralgia, or recurrence.

Conclusion After maternal varicella during pregnancy, herpes zoster may occur in the first year of life in a completely asymptomatic child at birth proving in utero infection. The presentation of the rash is characteristic; but otherwise, the condition differs from that in adults in that it is mild and not associated with postherpetic neuralgia. In uncomplicated cases, conservative treatment measures support the quick resolution with no sequelae.

\section{P589 CUTIS MARMORATA TELANGIECTATICA CONGENITA}

${ }^{1}$ Amel Ben Hamed, ${ }^{1}$ Afef Ben Thabet, ${ }^{1}$ Chiraz Regaieg*, ${ }^{1}$ Manel Charfi, ${ }^{1}$ Ridha Regaieg, ${ }^{1}$ Nedia Hmida, ${ }^{2}$ Abderahmen Masmoudi, ${ }^{2}$ Hamida Turki, ${ }^{1}$ Amira Bouraoui, ${ }^{1}$ Abdellatif Gargouri. 'Department of Neonatology, Hédi Chaker Hospital, Sfax, Tunisia; ${ }^{2}$ Department of Dermatology, Hédi Chaker hospital, Sfax, Tunisia

\subsection{6/archdischild-2019-epa.923}

Background Cutis marmorata telangiectatica congenita (CMTC) is a rare congenital cutaneous vascular anomaly. About 300 cases were reported in the littérature. It is associated persistent cutis marmorata, telangiectasia, and phlebectasia.

Case report We report a case of male neonate who has multiple bruises and purple macules on the skin anastomosed making a reticulated appearance as a spider's web, those skin lesions cover the trunk and legs but did not affect the face and did not disappear during the warming of the baby. Limits between normal and involved skin were atrophic. Given the constellation of clinical finding, Cutis Marmorata Telangiectatica Congenita (CMTC) was diagnosed. 